\title{
Ecological rationality and evolution: the mind really works that way?
}

\section{Gorka Navarrete* and Carlos Santamaría}

Cognitive Psychology Department, Universidad de La Laguna, Santa Cruz de Tenerife, Spain

*Correspondence: gorkang@gmail.com

There is a profound and ongoing debate in psychology on how humans face a complex task as probabilistic reasoning. The birth of an idea that is still prevalent and is one of the cornerstones of this debate could be placed at the time of the Enlightenment, in the early eighteenth century. By then, reason was considered a tool with admirable precision that, when properly trained, was capable of giving (objective) access to the marvels of the universe. The value given to the reason of those that mastered his secrets reached the point where, when discrepancies arose between probability theory and the judgment of the wise men, the theories were changed (Hacking, 1975; Daston, 1980).

Years passed, and after the birth of experimental psychology, the trickle of contradictory results between what was expected by the theories and the actual people's behavior began to be difficult to ignore. An alternative vision appeared and placed its focus away from the potentially perfect enlightened reason, paying more attention to its limits. The mind started to be seen as a general purpose information processing machine, but with limitations (e.g., working memory). Evidence emerged of different types of bias, cognitive shortcuts (heuristics) and, therefore, normative models of human behavior had to include amendments that remove them from the mathematical or statistical perfection of yesteryear. An example of bias on a simple principle is the Conjunction Fallacy. Obviously if we compare $p(\mathrm{~A})$ with $p(\mathrm{~A}$ and $\mathrm{B})$ the probability of the latter cannot exceed that of the former. However, under certain circumstances people seem to skip this principle. The best known example (from Tversky and Kahneman, 1974) showed how after a description of a progressive (feminist-like) person people judged the sentence "Linda is a bank teller and is active in the feminist movement" as greater than that of "Linda is a bank teller" as a description of Linda. The line of work behind much of these results, called Heuristics and Biases (e.g., Tversky and Kahneman, 1974, 1983), earned a Nobel Prize to Daniel Kahneman.

But the dispute wasn't settled. In response to the above vision emerged a group that emphasized a different place, the second blade of Simon's scissors: the outside world (Gigerenzer et al., 1988; Gigerenzer, 1991, 1993; Cosmides and Tooby, 1996). For Herbert Simon, when studying human cognition it is meaningless to consider only the mind. Like scissors are just a useless piece of metal in the absence of one of the blades, ignoring the world around us makes futile any effort to understand the intimate secrets of cognition, as it is a reflection of a subtle dance between mind and environment (Simon, 1990, p. 7).

Ecological Rationality proposed an alternative to the vision of the mind as a general purpose information processing machine. They suggested that the mind was in fact a set of tools designed by natural selection to deal with different aspects of reality. So the limitations became opportunities thanks to natural selection. From the Ecological Rationality point of view, phylogenetic history shaped us using the environment as a canvas, filling the gaps with adaptive functions (through algorithms or specialized modules) that provide well-adjusted answers (Brase and Barbey, 2006). One of the most important conclusions to be drawn from this view is that when studying the mind, paying attention to the world around is not only very useful, but probably essential, since regularities in its structure allows us to infer the domains for which there is cognitive adaptations (Todd and Gigerenzer, 2000, 2002, 2007).

From these very sensible ideas, an important amount of research designed to show various sides of the influence of the environment on the human mind and our behavior has been conducted. Studies appeared highlighting the improved performance in probabilistic problems using natural frequencies instead of probabilities of simple events ( 5 out of 20 instead of $25 \%$; Gigerenzer and Hoffrage, 1995). Others on how the Recognition Heuristic (Pachur et al., 2011) may lie behind decision-making mechanisms like Take The Best (TTB), which using only the first discriminative clue is able to outperform more complex tools such as Artificial Neural Networks (Todd and Gigerenzer, 2000), etc.

A substantial part of the strength of evolutionary arguments lies in the intuitive appeal they have. The cases discussed above, both the issue of representation format (natural frequencies versus probabilities) and decision heuristics like TTB, are good examples of evolutionary arguments. In the first case, the view that there is a modular adaptation, heuristic, or any other sort of specific brain machinery to process probabilistic information in the form of natural frequencies rather than probabilities, is based on empirical results from a particular type of problem showing that people understand frequentist information better and make more precise calculations based on it (Gigerenzer and Hoffrage, 1995). The intuitively impeccable idea that throughout our evolutionary history we have been surrounded by simple events (from which the natural frequencies arise) and not probabilities, as they are a relatively recent invention, supported these results.

But science does not advance, exclusively, on the shoulders of bright intuitively impeccable ideas. These ideas and experiments supporting them must be tested, replicated, understood, dissected, etc. And the intuitions have to be supported empirically beyond doubt. It is in this process where Ecological Rationality has shown a less impeccable profile, using hypotheses generated by evolutionary arguments in the demonstration plane. Based on a more complete understanding and manipulation of the classic experiments and on a few new ones, more simple alternative hypotheses have emerged. And they do not appeal to mechanisms related to evolution (e.g., Lesage et al., 
unpublished data; for a review, see Barbey and Sloman, 2007). These hypotheses talk about the structure of information, arithmetic complexity, cognitive resources, etc. Although some of these ideas where present in a more rudimentary shape in the original work of the Ecological Rationality proponents, the alternatives are much more complete and explain, in a simpler way (no need for evolutionary cover-stories), a wider phenomenon. Occam would be proud.

We also used before an example about how, from evolutionist positions, it is argued that certain innate heuristic decision mechanisms perform better than more complex and less efficient ones. Again, the explanation used regarding the origin of these systems has to do with untestable evolutionary hypotheses. And again, empirical evidence showed how the advantage of these heuristic mechanisms is minimal and occurs in very specific types of problems, and that, tools like Nearest Neighbor or Neural Networks, when properly used, can produce equal or superior results (Chater et al., 2003). These kinds of algorithms are related to our empirical knowledge of human learning rather than phylogenetic postulates.

The above examples are maybe just hand-picked representatives from a large battle being waged between supporters of a vision focused on the biases and limitations of the human mind, and supporters of an approach that stresses the need for a more ecological experimentation in natural contexts, given that it is likely that the human mind has adapted to them over our evolutionary history. Both positions are probably partly right and valuable. The approach of ecological rationality, or generally those that seek answers beyond the present, can be very useful but it's easy to end up in the alley of bad science if used incorrectly. On the other hand, the positions based, mostly, on finding faults can become too opportunistic, and their empirical testing be artificial in excess (Cohen, 1981), forgetting the overall objective, which is to understand how the mind works.

The modular view of the mind used in the last few years by Evolutionary Psychology in general, and Ecological Rationality in particular, has become a widespread cliché to explain complex cognitive phenomenon. Fodor himself warned against an excessive use of modules to explain high level cognition. The modules, as defined by Fodor, are I/O low level black boxes and anything related to reasoning, probabilistic, or otherwise, wouldn't fit inside. Reasoning requires the participation of multiple complex systems and it is, almost by definition, the opposite of what a proper Fodorian module should be (Fodor, 1983, 2000). Of course, other relatively recent modularity explanations are less restrictive regarding the criteria for modules (Barrett and Kurzban, 2006). As an example, a successful alternative approach to modularity would be the one that crystallized on ACT-R (Anderson, 1990; Anderson et al., 2004). What distinguishes ACT-R is its focus on the integration of cognition (see also, Newell, 1990), as it is focused on developing a general theory of cognition. A critical distinction with Ecological Rationality is the generality of the functioning of the modules. ACT-R claims more general oriented modules (e.g., the perceptual modules) and Ecological Rationality proposes more specific modules (e.g., natural frequencies module). Finally, contrary to Ecological Rationality, ACT-R foundations are not linked to human evolution in a critical way.

Although it is possible that the environment shapes the mind, at least to some extent, the evolutionary hypothesis should always be regarded with greater skepticism, least we cut ourselves with Simon's scissors (Buss et al., 1998). The evolutionary plausibility of mechanisms based on the human ability to adapt to the environment it is a phenomenal source for new ideas and hypothesis but it shouldn't be used as a way to demonstrate the same ideas it helps generate. The specific problems which could have faced the human mind in the Pleistocene are candidates to hypothesize mental mechanisms. However, some restrictions should be taken into account: first, not any kind of mechanism is possible in the human mind. The mind as any evolved machinery includes restrictions and not any useful tool should become a reality (wheels are useful for locomotion in some conditions but evolution preferred legs). Also, some problems are intractable for a modular specific mechanism because they need to allow for the context to be checked (that includes any task facing the frame problem; McCarthy and Hayes, 1969). And, of course, once demonstrated that a mechanism is possible it should still be demonstrated that it really happens in the actual mind and this is a task for the empirical testing. Nonetheless, not only evolutionary hypotheses must be subjected to such scrutiny. Any assumptions, scientific, or otherwise, should be challenged, reviewed, understood and shredded. This is how good science is done and, in general, moves forward as toward a more complete and accurate understanding of the world.

\section{ACKNOWLEDGMENTS}

BSO2003-0894. PSI2011-26386. ULLAPD-

08/01. AVANZA; TSI-020100-2008-337.

CICYT; TIN2008-06867-C02-01/TI.

Proyecto Estructurante Neurocog, awarded by Agencia Canaria de Investigación, Innovación y Sociedad de la Información and co-financed by FEDER funds and the Universidad de La Laguna.

\section{REFERENCES}

Anderson, J.R. (1990). The Adaptive Character of Thought. Hillsdale, NJ: Lawrence Erlbaum Associates.

Anderson, J. R, Bothell, D., Byrne, M. D., Douglass, S., Lebiere, C., and Qin, Y. (2004). An integrated theory of the mind. Psychol. Rev. 111, 1036-1060.

Barbey, A., and Sloman, S. (2007). Base-rate respect: from ecological rationality to dual processes. Behav. Brain Sci. 30, 241-254.

Barrett, H. C., and Kurzban, R. (2006). Modularity in cognition: framing the debate. Psychol. Rev. 113, 628-647.

Brase, G., and Barbey, A. (2006). Mental Representations of statistical information. Adv. Psychol. Res. 41, 91-113.

Buss, D. M., Haselton, M. G., Shackelford, T. K., Bleske, A. L., and Wakefield, J. C. (1998). Adaptations, exaptations, and spandrels. Am. Psychol. 53, 533-548.

Chater, N., Oaksford, M., Ramin, N., and Redington, M. (2003). Fast, frugal, and rational: how rational norms explain behavior. Organ. Behav. Hum. Decis. Process 90, 63-86.

Cohen, L. J. (1981). Can be experimentally demonstrated human irrationality. Behav. Brain Sci. 4, 317-329.

Cosmides, L., and Tooby, J. (1996). Are humans good intuitive statisticians after all? Rethinking some conclusions from the literature on judgment under uncertainty. Cognition 58, 1-73.

Daston, L. J. (1980). Probabilistic expectation and rationality in classical probability theory in papers in honor of Erwin N. Hiebert. Hist. Math. 7, 234-260.

Fodor, J. (1983). The Modularity of Mind. Cambridge, MA: MIT Press.

Fodor, J. (2000). The Mind Doesn't work That Way: The Scope and Limits of Computational Psychology. Cambridge, MA: MIT Press.

Gigerenzer, G. (1991). How to make cognitive illusions disappear: beyond "heuristics and biases." Eur. Rev. Soc. Psychol. 2, 83-115.

Gigerenzer, G. (1993). "The bounded rationality of probabilistic mental models," in Rationality: Psychological and Philosophical Perspectives, eds K. I. Manktelow and D. E. Over (London: Routledge), 284-313. 
Gigerenzer, G., Hell, W., and Blank, H. (1988). Presentation and content: the use of base rates as a continuous variable. J. Exp. Psychol. Hum. Percept. Perform. 14, 513-525.

Gigerenzer, G., and Hoffrage, U. (1995). How to improve Bayesian reasoning without instruction: frequency formats. Psychol. Rev. 102, 684-704.

Hacking, I. (1975). The Emergence of Probability: A Philosophical Study of Early Ideas About Probability, Induction and Statistical Inference. London: Cambridge University Press.

McCarthy, J., and Hayes, P. J. (1969). "Some philosophical problems from the standpoint of artificial intelligence," in Machine Intelligence, Vol. 4, eds D. Michie and B. Meltzer (Edinburgh: Edinburgh University Press), 463-502.

Newell, A. (1990). Unified Theories of Cognition. Cambridge, MA: Harvard University Press.
Pachur, T., Todd, P.M., Gigerenzer, G., Schooler, L. J., and Goldstein, D. G. (2011). The Recognition Heuristic: a review of theory and tests. Front. Psychol. 2:147. doi: 10.3389/fpsyg.2011.00147

Simon, H.A. (1990). Invariants of human behavior. Annu. Rev. Psychol. 41, 1-20.

Todd, P. M., and Gigerenzer, G. (2000). Simple heuristics that make us smart. Behav. Brain Sci. 23, 727-741.

Todd, P., and Gigerenzer, G. (2002). Shepard's mirrors or Simon's scissors? Behav. Brain Sci. 24, 704-705.

Todd, P., and Gigerenzer, G. (2007). Environments that make us smart: ecological rationality. Curr. Dir. Psychol. Sci. 16, 167-171.

Tversky, A., and Kahneman, D. (1974). Judgement under uncertainty - Heuristics and biases. Science 185, 1124-1131.
Tversky, A., and Kahneman, D. (1983). Extensional versus intuitive reasoning - the conjunction fallacy in probability judgement. Psychol. Rev. 90, 293-315.

Received: 18 July 2011; accepted: 12 September 2011; published online: 30 September 2011.

Citation: Navarrete Gand Santamaría C (2011) Ecological rationality and evolution: the mind really works that way? Front. Psychology 2:251. doi: 10.3389/fpsyg.2011.00251 This article was submitted to Frontiers in Cognitive Science, a Specialty of Frontiers in Psychology.

Copyright (c) 2011 Navarrete and Santamaría. This is an open-access article subject to a non-exclusive license between the authors and Frontiers Media SA, which permits use, distribution and reproduction in other forums, provided the original authors and source are credited and other Frontiers conditions are complied with. 